\title{
Removing Hydrochloric Acid Exhaust Products from High Performance Solid Rocket Propellant Using Aluminum-Lithium Alloy
}

\author{
Brandon C. Terry ${ }^{*[a]}$, Travis R. Sippel ${ }^{[b]}$, Mark A. Pfeil ${ }^{[a]}$, \\ I. Emre Gunduz ${ }^{[c]}$, Steven F. Son ${ }^{[c]}$
${ }^{a}$ School of Aeronautics and Astronautics, Purdue University, Zucrow Laboratories, 500 Allison Rd, West Lafayette, IN 47907, United States, *E-mail: terry13@ purdue.edu, Fax: (765) 494-0530
${ }^{\mathrm{b}}$ Department of Mechanical Engineering, Iowa State University, 2025 Black Engineering, Ames, IA 50011, United States \\ ${ }^{\mathrm{c}}$ School of Mechanical Engineering, Purdue University, Zucrow Laboratories, 500 Allison Rd, West Lafayette, IN \\ 47907, United States
}

\begin{abstract}
Hydrochloric acid $(\mathrm{HCl})$ pollution from perchlorate based propellants is well known for both launch site contamination, as well as the possible ozone layer depletion effects. Past efforts in developing environmentally cleaner solid propellants by scavenging the chlorine ion have focused on replacing a portion of the chorine-containing oxidant (i.e., ammonium perchlorate) with an alkali metal nitrate. The alkali metal (e.g., Li or $\mathrm{Na}$ ) in the nitrate reacts with the chlorine ion to form an alkali metal chloride (i.e., a salt instead of $\mathrm{HCl}$ ). While this technique can potentially reduce $\mathrm{HCl}$ formation, it also results in reduced ideal specific impulse $\left(\mathrm{I}_{\mathrm{SP}}\right)$. Here, we show using thermochemical calculations that using aluminum-lithium (Al-Li) alloy can reduce $\mathrm{HCl}$ formation by more than $95 \%$ (with lithium contents $\geq 15$ mass \%) and increase the ideal $\mathrm{I}_{\mathrm{SP}}$ by $\sim 7$ seconds compared to neat aluminum (using 80/20 mass \% Al-Li alloy). Two solid propellants were formulated using 80/20 Al-Li alloy or neat aluminum as fuel additives. The halide scavenging effect of Al-Li propellants was verified using wet bomb combustion experiments $(75.5 \pm 4.8 \%$ reduction in $\mathrm{pH}, \propto[\mathrm{HCl}]$, when compared to neat aluminum). Additionally, no measurable $\mathrm{HCl}$ evolution was detected using differential scanning calorimetry coupled with thermogravimetric analysis, mass spectrometry, and Fourier transform infrared absorption.
\end{abstract}


Keywords: solid propellant; halide scavenging; hydrochloric acid; green propellant 


\section{Introduction}

Ammonium perchlorate $\left(\mathrm{AP}, \mathrm{NH}_{4} \mathrm{ClO}_{4}\right)$ is the most common oxidizer used in solid composite rocket propellants [1-3] because of its high oxygen content (54.5 mass \%) and large gas volume that is generated during combustion. However, the chlorine (30.2 mass \%) in the oxidant favors formation of gaseous hydrochloric acid $(\mathrm{HCl})$ as a primary product species [2-6]. As much as $98 \%$ of the available chlorine ions may be converted to $\mathrm{HCl}$ gas in common $\mathrm{AP}$ composite propellant formulations (APCP), composed of aluminum/AP/binder. The negative environmental and corrosive effects of $\mathrm{HCl}$ pollution have been widely documented regarding both ground effects around the launch/test pad [4-7] as well as the ozone layer [4-6, 8, 9]. Additionally, it has been shown that $\mathrm{HCl}$ gas forms nucleation sites for aerosolized water products, which contribute to secondary smoke formation from the exhaust plume (a negative trait for missile flight detection) [5, 8]. Unfortunately, there are currently no fielded chlorine-free solid oxidizers that have comparable performance to AP, so alternative approaches are needed to mitigate the environmental impact of APCP.

There are three methods that have been investigated for $\mathrm{HCl}$ reduction in composite rocket propellants [3, 5]: (1) reduced chlorine propellants [10]; (2) neutralization of the $\mathrm{HCl}$ acid in the combustion plume [11-14]; and (3) scavenging of the chlorine ion using alkali metals [1517]. All techniques were successful at reducing $\mathrm{HCl}$ in the APCP combustion plume, but they did so with decrement of ideal performance (specific impulse, I $_{S P}$ ), increase in detonability [18], and/or required low altitudes to function. While previous efforts to scavenge the chlorine ion have predicted poor ideal performance, other methods of alkali metal introduction may yield improved performance.

Scavenged propellants use strongly halophilic materials (e.g., alkali metals) to "scavenge" chlorine ions during combustion to form alkali metal chlorides (i.e., salts) $[5,16,17]$. Because of their high reactivity, neat elemental alkali metals are not used in APCP formulations. Therefore, alkali metal nitrates (e.g., $\mathrm{LiNO}_{3}$ and $\mathrm{NaNO}_{3}$ ) have been used to stably introduce the strongly halophilic material, replacing a stoichiometric amount of AP $[5,15,17]$. While these formulations have been shown to significantly reduce $\mathrm{HCl}$ formation during combustion, they do so at an unacceptable loss to ideal performance.

In order to improve the performance of scavenged propellants, stabilized oxophilichalophilic fuel particles may be considered instead as a fuel replacement. In the 1960s, 
theoretical studies into dual oxophilic-halophilic fuel combinations (typically in the form of various hypothetical beryllium-metal composites [19]) were investigated as a means to improve ideal specific impulse when combined with a chlorine-containing oxidant, such as AP [19-22]; however, their potential use as $\mathrm{HCl}$ scavengers was not investigated. Stabilization of the strongly halophilic material may be accomplished through alloying of the oxophilic-halophilic fuels, mechanical alloying/mixing, or encapsulation within an oxophilic matrix. In each of these cases, the amount of unprotected halophilic material on the particle surface is minimized, significantly reducing reactivity or stability complications.

One such oxophilic-halophilic fuel of potential interest is the aluminum-lithium (Al-Li) binary alloy. Aluminum is strongly oxophilic and has been widely used in commercial APCP formulations, and lithium is an alkali metal with a high heat of chlorination [19]. Lithium also has a relatively low molecular mass, which can improve ideal performance [23, 24]. Al-Li alloys are already commonly used as structural materials in the aerospace industry [25], making their fabrication and usage already well established, at least for low lithium contents. Additionally, the $\mathrm{LiCl}$ salt as a combustion product has minimal health hazards and is commercially used in fireworks as a magenta (or "carmine") flame colorant [26].

It is the objective of this work to investigate the ideal performance of various aluminumlithium binary alloys in APCP formulations and to investigate the delivered scavenging effects of APCP using the 80/20 mass \% Al-Li alloy (LiAl intermetallic phase) as an APCP metal fuel additive in laboratory experiments.

\section{Experimental Section}

\subsection{Thermochemical Equilibrium Calculations}

Thermoequilibrium calculations were completed using Cheetah 7.0 equilibrium code (JCZS product library and JCZ3 gas equation of state) [27], assuming a chamber pressure of 6.89 $\mathrm{MPa}$ and standard expansion to atmospheric pressure. Hydroxyl-terminated polybutadiene (HTPB) was used as the binder for all APCP simulations. The following Al-Li alloy compositions were used in these simulations (mass \% Li): 0, 5, 10, 15, 20, 25, 30, 100. Additionally, the $\mathrm{Al} /\left(56 / 44\right.$ mass $\left.\% \mathrm{AP} / \mathrm{NaNO}_{3}\right) / \mathrm{HTPB}$ system was also investigated as a baseline scavenged propellant formulation [3]. A total of 10,000 simulations were performed for 
each ternary system, systematically varying the oxidizer to fuel ratio $(\mathrm{O} / \mathrm{F})$ and the mass percent of fuel additive in the total fuel (total fuel $=$ binder + fuel additive). Post processing of these calculations was performed in MATLAB.

All Al-Li alloy fuel additives were assumed to be a physical mixture of aluminum and lithium for all applicable equilibrium calculations, and the binary Al-Li alloy ratio was changed with each batch of simulations. Heats of formation, $\Delta_{f} H$, of the different Al-Li ratios actually vary due to alloy mixing and/or intermetallic formation enthalpy and are uncertain. It is recognized that this assumption yields $\mathrm{I}_{\mathrm{SP}}$ values that are artificially high due to increased ideal combustion temperatures. However, this error is expected to be minor. The LiAl intermetallic phase has the largest $\Delta_{f} H$ magnitude in the Al-Li alloy range considered (measured to be between -9.77 to $-21.8 \mathrm{~kJ} \mathrm{~mol}^{-1}$ [28-35]), which yields a maximum $\mathrm{I}_{\mathrm{SP}}$ error of only $0.7 \%$.

The primary performance parameter commonly used to evaluate rocket motor performance is specific impulse, which is a measure of the total impulse per unit mass of propellant. Since the halide scavenging effect was also of importance for this study, the following relation was assumed and evaluated as a "high performance halide scavenger" (HPHS) parameter:

$$
H P H S=\left(\frac{I_{S P}}{I_{S P, \max }}\right) \times[100 \%-(\% \mathrm{Cl} \rightarrow H C l)]
$$

where $I_{S P}$ is the specific impulse at the current mixture ratio, $I_{S P, \max }$ is the maximum specific impulse obtainable with the ternary system, and $\% \mathrm{Cl} \rightarrow \mathrm{HCl}$ is the percentage of available chlorine forming $\mathrm{HCl}$ at the current mixture ratio and at expansion to $1 \mathrm{~atm}$ pressure. This chosen performance parameter places an equal weight on both specific impulse and $\mathrm{HCl}$ reduction for the purpose of evaluating a "cleaner," high performance propellant formulation. An HPHS value of $100 \%$ indicates that complete $\mathrm{HCl}$ reduction is occurring at the ternary system's peak specific impulse.

\subsection{Solid Propellant Formulation and Combustion Characteristics}

Two solid composite propellants were prepared using the following fuel additives: A.) neat aluminum (Alfa Aesar, -325 mesh, 99.5\% purity); and B.) 80/20 mass \% Al-Li alloy (stable LiAl intermetallic phase $[28,32]$ ) (Sigma Aldrich). This is the only high lithium content Al-Li 
alloy commercially available at this time within the lithium content range of interest, and it was chosen for the propellant formulations because of that constraint.

The as-received 80/20 Al-Li alloy was sieved to -325 mesh $(<44 \mu \mathrm{m})$ to be comparable with the as-received neat aluminum powder. The particle size distributions for both powders were determined by laser diffraction (Malvern Mastersizer Hydro 2000 $\mu \mathrm{P}$ ) using isopropyl alcohol as the dispersant medium. Surface imaging of both powders was performed by scanning electron microscopy (SEM, FEI Quanta 3D-FEG).

The constituents used for the APCP formulations included: ammonium perchlorate (ATK, $20 \mu \mathrm{m}$ and $200 \mu \mathrm{m}$, size distributions can be found in Ref. [36]), and HTPB (Firefox, $\mathrm{R} 45 \mathrm{M}$ ) cured with an aromatic polyisocyanate (Desmodur, E744) as the binding agent. The following formulation was used to prepare approximately 20 grams of propellant for each mixture:

- $\quad$ Metal Additive: $26.8 \%$

- $\quad$ Coarse AP, $200 \mu \mathrm{m}: 49.2 \%$

- $\quad$ Fine AP, $20 \mu \mathrm{m}: 12.3 \%$

- $\quad$ HTPB $(11.5 \%$ curative): $11.7 \%$

For comparison with ideal performance predictions, these ratios correspond to an O/F of 1.60, a fuel additive mass $\%$ of $69.6 \%$, and a solids loading of $88.3 \%$. Note that the metal content is high in order to obtain the lithium/AP ratio required to fully scavenge the available chlorine.

No incompatibilities were observed with the aromatic polyisocyanate curative, though the working time of the wetted propellant was short (approximately 30 minutes). A propellant batch was attempted with an aliphatic diisocyanate curative (Isophorone diisocyanate, IPDI) in order to extend the working time with the wetted propellant (several hours), but an incompatibility resulted in significant propellant outgassing during curing, forming a foamy, porous propellant.

Propellant constituents were resonant mixed (Resodyn LabRAM resonant mixer) in a 60 $\mathrm{mL}$ container (McMaster-Carr 42905T23) for $10 \mathrm{~min}$ at 90\% intensity. Strands were then packed into $5.8 \mathrm{~mm}$ diameter cylindrical molds and cured in air for approximately 3 days at room temperature. The burning characteristics of the propellants were investigated using a color highspeed camera (Vision Research, Phantom v7.3) at $1000 \mathrm{fps}$ in a vented fume hood. 


\subsection{Hydrochloric Acid Detection}

Both the neat aluminum and Al-Li alloy propellants were burned in a closed $130 \mathrm{~mL}$ stainless steel Parr cell filled with $50 \mathrm{ml}$ distilled water (i.e., wet bomb experiments), since this method has been used in previous studies [3, 11, 12]. A schematic of the wet bomb experiment is shown in Fig. 1. Propellant strands $(50.0 \pm 0.2 \mathrm{mg})$ were burned in argon at $2.5 \mathrm{MPa}$. The $\mathrm{pH}$ of the distilled water was measured with a digital $\mathrm{pH}$ meter (Omega, $\mathrm{PHH}-37$ ) before and after each wet bomb experiment. The experiment was repeated three times for each propellant type.

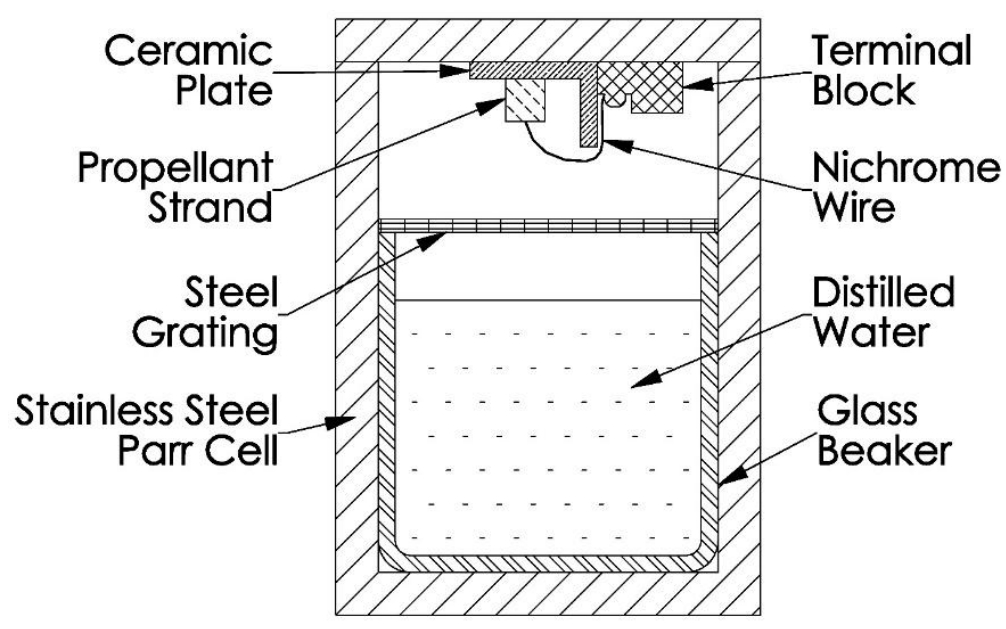

Figure 1. A schematic showing the wet combustion bomb experiment used to quantify the change in $\mathrm{HCl}$ concentration.

Neat powders of AP $(200 \mu \mathrm{m}$, Firefox $)$ and stirred mixtures of 30/70 mass \% metal/AP were also analyzed using simultaneous differential scanning calorimetry / thermogravimetric analysis (DSC/TGA) (Netzsch Jupiter STA449 F1) with online gas analysis via mass spectrometry (MS, Netzsch Aeolos) and Fourier transform infrared absorption (FTIR, Bruker Tensor 37). The 30/70 mass $\%$ ratio of metal/AP was chosen, as it is similar to the metal/AP ratio of the experimental propellants. Experiments were conducted on $3.1 \mathrm{mg}$ samples of AP and 4.1 mg samples of metal/AP such that the total amount of AP contained within each sample was similar. 
Prior to starting experiments, the DSC/TGA instrument's platinum furnace was evacuated and backfilled with purge gas three times. The samples were heated from room temperature to $700{ }^{\circ} \mathrm{C}$ at a heating rate of $20{ }^{\circ} \mathrm{C} \mathrm{min}-1$ under a steady flow of $40 \mathrm{~mL} \mathrm{~min}{ }^{-1}$ of ultra-high purity argon (99.999 vol.\%). The instrument exhaust was coupled to FTIR and MS instrumentation using a heated $\left(200{ }^{\circ} \mathrm{C}\right)$ manifold and silica capillaries. The capillary was interfaced with the FTIR instrument's liquid nitrogen-cooled MCT detector via a heated $\left(200{ }^{\circ} \mathrm{C}\right)$ Bruker TGA-IR light pipe. During DSC/TGA experiments, MS and IR data was recorded at temperature increments of approximately $3{ }^{\circ} \mathrm{C}$ with a mass range of 10 to 100 and IR spectral resolution of $2 \mathrm{~cm}^{-1}$, respectively. Data was post-processed using the Netzsch Proteus software, NISTMS, Bruker Opus software packages, and NIST/EPA MS and FTIR libraries.

\section{Results and Discussion}

\subsection{Thermochemical Equilibrium Calculations}

Initial investigations of Al-Li based APCP involved theoretical performance calculations using various Al-Li ratios, as well as neat aluminum, neat lithium, and a baseline scavenged propellant replacing a portion of $\mathrm{AP}$ with $\mathrm{NaNO}_{3}$. This work was completed to determine a range of lithium contents for which the Al-Li system could act as a high performance halide scavenger. Examples of these ternary system simulations are presented in Fig. 2. The mixture ratios that yielded the highest specific impulse for each fuel additive are tabulated in Table 1 and their corresponding performance values are tabulated in Table 2. The mixture ratio with the highest HPHS value for the 80/20 Al-Li system is denoted by an asterisk (*) in Tables 1-2, and is the mixture ratio that was used for all experimental results.

The performance values in Table 2 include: specific impulse, density impulse, enthalpy change across the nozzle, chamber temperature, exhaust molecular mass, and the conversion of chlorine and alkali metal to $\mathrm{HCl}$ and $\mathrm{MCl}$ ("M" denotes alkali metal). When evaluating the results in Table 2, it is important to note that specific impulse has the following relations [24]:

$$
I_{S P} \equiv \frac{I}{m_{p} g} \propto \sqrt{\Delta h} \propto \sqrt{\frac{T_{0}}{\mathcal{M}}},
$$


where $I$ is the total impulse, $m_{p}$ is the propellant mass, $g$ is standard gravity, $\Delta h$ is the enthalpy change across the nozzle, $T_{0}$ is the stagnation temperature of the combustion products (equivalent to the chamber temperature $T_{\text {Chamber }}$ in an ideal rocket combustor), and $\mathcal{M}$ is the molecular mass of the combustion products. The first proportionality results from the assumptions that the exhaust velocity is constant (i.e., steady state flow conditions) and that there is isentropic flow through the nozzle [23, 24]. This is the relationship that Cheetah 7.0 equilibrium code [27] uses to calculate $\mathrm{I}_{\mathrm{SP}}$. The second proportionality makes the assumptions that the exhaust products are a thermally and calorically perfect gas [23, 24] (likely not good assumptions when condensed phase product species are present) and shows that high chamber temperatures and low product molecular mass improve specific impulse. 
Table 1. The mixture ratios yielding the highest predicted specific impulse for each of the ternary additive/AP/HTPB propellants investigated. The mixture ratio denoted $*$ indicates the mixture ratio with the highest predicted HPHS value for that ternary system.

\begin{tabular}{|c|c|c|c|c|c|c|c|c|c|}
\hline Additive & $\begin{array}{c}\text { AP } \\
{[\text { mass \%] }}\end{array}$ & $\begin{array}{r}\mathrm{NaNO}_{3} \\
{[\text { mass \%] }} \\
\end{array}$ & $\begin{array}{c}\text { HTPB } \\
{[\text { mass \%] }}\end{array}$ & $\begin{array}{c}\mathrm{Al} \\
{[\mathrm{mass} \%]} \\
\end{array}$ & $\begin{array}{c}\mathrm{Li} \\
{[\text { mass \%] }}\end{array}$ & $\begin{array}{c}\text { Additive Content } \\
{[\%]} \\
\end{array}$ & $\begin{array}{l}\mathrm{O} / \mathrm{F} \\
{[-]} \\
\end{array}$ & $\begin{array}{c}\text { Solids Loading } \\
{[\%]} \\
\end{array}$ & $\begin{array}{c}\text { Theoretical Density } \\
{\left[\mathrm{g} \mathrm{cm}^{-3}\right]} \\
\end{array}$ \\
\hline Neat Al & 66.7 & - & 11.5 & 21.8 & - & 65.6 & 2.0 & 88.5 & 2.00 \\
\hline Neat Li & 85.9 & - & 8.2 & - & 5.9 & 41.6 & 6.1 & 91.8 & 1.36 \\
\hline Al-Li (5 wt.\% Li) & 65.6 & - & 11.1 & 22.2 & 1.2 & 67.9 & 1.9 & 88.9 & 1.99 \\
\hline Al-Li (10 wt.\% Li) & 64.2 & - & 10.8 & 22.5 & 2.5 & 69.9 & 1.8 & 89.2 & 1.97 \\
\hline Al-Li (15 wt. \% Li) & 63.0 & - & 11.0 & 22.0 & 3.9 & 70.2 & 1.7 & 89.0 & 1.95 \\
\hline Al-Li (20 wt.\% Li) & 63.0 & - & 11.0 & 20.7 & 5.2 & 70.2 & 1.7 & 89.0 & 1.92 \\
\hline *Al-Li (20 wt.\% Li) & 61.5 & - & 11.7 & 21.4 & 5.4 & 69.6 & 1.6 & 88.3 & 1.91 \\
\hline Al-Li (25 wt.\% Li) & 63.0 & - & 11.0 & 19.5 & 6.5 & 70.2 & 1.7 & 89.0 & 1.89 \\
\hline Al-Li (30 wt. \% Li) & 63.0 & - & 11.0 & 18.2 & 7.8 & 70.4 & 1.7 & 89.0 & 1.86 \\
\hline Neat $\mathrm{Al}, \mathrm{NaNO}_{3}$ & 36.0 & 28.3 & 11.9 & 23.7 & - & 66.6 & 1.8 & 88.1 & 2.09 \\
\hline
\end{tabular}

Table 2. The predicted combustion and motor performance for each of the mixture ratios tabulated in Table 1. The "M" species represents the system's alkali metal (i.e., Li and $\mathrm{Na}$ ). The mixture ratio denoted $*$ indicates the mixture ratio with the highest predicted HPHS value for that ternary system.

\begin{tabular}{|c|c|c|c|c|c|c|c|c|c|}
\hline Additive & $\begin{array}{c}\operatorname{Max} I_{\mathrm{SP}} \\
{[\mathrm{s}]} \\
\end{array}$ & $\begin{array}{c}\text { Density Impulse } \\
{\left[\mathrm{g}-\mathrm{s} \mathrm{cm}^{-3}\right]}\end{array}$ & $\begin{array}{c}\Delta \mathrm{h}_{\text {Chamber-Exit }} \\
{\left[\mathrm{kJ} \mathrm{g}^{-1}\right]} \\
\end{array}$ & $\begin{array}{c}\mathrm{T}_{\text {Chamber }} \\
{[\mathrm{K}]} \\
\end{array}$ & $\begin{array}{l}\text { Mol. Mass } \\
{\left[\mathrm{kg} \mathrm{kmol}^{-1}\right]}\end{array}$ & $\begin{array}{c}\mathrm{Cl} \rightarrow \mathrm{HCl} \\
{[\%]} \\
\end{array}$ & $\begin{array}{c}\mathrm{Cl} \rightarrow \mathrm{MCl} \\
{[\%]} \\
\end{array}$ & $\begin{array}{c}\mathrm{M} \rightarrow \mathrm{MCl} \\
{[\%]} \\
\end{array}$ & $\begin{array}{c}\text { HPHS } \\
{[\%]} \\
\end{array}$ \\
\hline Neat Al & 264.8 & 528.7 & 3.37 & 3614 & 27.9 & 98.3 & - & - & 1.7 \\
\hline Neat Li & 263.4 & 358.1 & 3.34 & 3204 & 27.3 & 1.8 & 95.0 & 82.1 & 98.2 \\
\hline Al-Li (5 wt.\% Li) & 267.3 & 531.1 & 3.44 & 3658 & 27.8 & 68.5 & 30.0 & 99.3 & 31.5 \\
\hline Al-Li (10 wt.\% Li) & 269.9 & 532.6 & 3.50 & 3679 & 27.6 & 34.0 & 65.0 & 98.6 & 66.0 \\
\hline Al-Li (15 wt. \% Li) & 271.8 & 529.3 & 3.55 & 3621 & 26.7 & 3.6 & 96.1 & 91.9 & 96.4 \\
\hline Al-Li (20 wt.\% Li) & 271.9 & 521.9 & 3.56 & 3553 & 26.2 & 1.9 & 97.8 & 70.3 & 98.1 \\
\hline *Al-Li (20 wt.\% Li) & 270.7 & 518.3 & 3.52 & 3450 & 25.5 & 0.3 & 99.0 & 67.1 & 99.1 \\
\hline Al-Li (25 wt.\% Li) & 272.7 & 515.7 & 3.58 & 3537 & 25.7 & 1.7 & 98.0 & 56.2 & 98.3 \\
\hline Al-Li (30 wt.\% Li) & 273.4 & 509.7 & 3.60 & 3547 & 25.3 & 1.5 & 98.2 & 46.9 & 98.5 \\
\hline Neat $\mathrm{Al}, \mathrm{NaNO}_{3}$ & 246.1 & 515.0 & 2.91 & 3508 & 30.7 & 15.2 & 84.2 & 77.5 & 84.8 \\
\hline
\end{tabular}



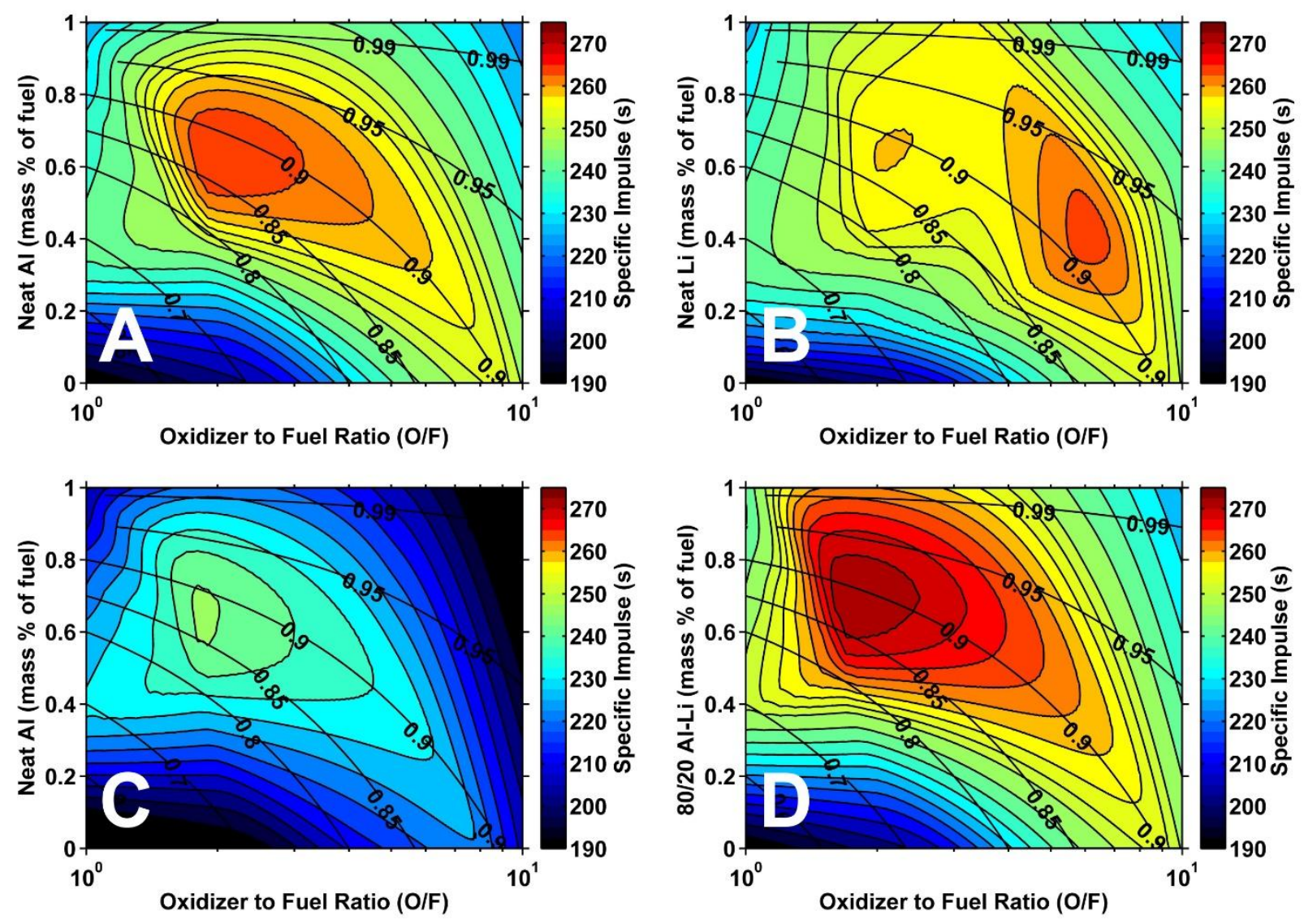

Figure 2. Thermochemical equilibrium predictions for fuel additive/AP/HTPB propellant formulations. The fuel additives are as follows: A.) neat $\mathrm{Al}$; B.) neat $\mathrm{Li}$; C.) neat $\mathrm{Al}$, but with a 56/44 mass \% AP/NaNO 3 oxidizer; and D.) 80/20 mass \% Al-Li alloy. Specific impulse contour lines above 250 seconds represent increments of 2.5 seconds and contour lines below 250 seconds represent increments of 5 seconds. The transverse contour lines represent propellant solids loading. A color version of this figure can be found in the online manuscript.

From a comparison of the performance maps for neat $\mathrm{Al}$ and neat Li (Figs. 2A, B), it is apparent that the neat $\mathrm{Al}$ fuel additive only has one global optimum value, whereas neat $\mathrm{Li}$ has two local optima. The ideal optimum $\mathrm{I}_{\mathrm{SP}}$ for neat aluminum corresponds to complete oxidation of the aluminum additive (forming liquid $\mathrm{Al}_{2} \mathrm{O}_{3}$ ), with enough remaining oxygen so that carbon in the binder forms $\mathrm{CO}$, all chlorine becomes $\mathrm{HCl}$, all remaining hydrogen becomes gaseous hydrogen $\left(\mathrm{H}_{2}\right)$, and all nitrogen becomes gaseous nitrogen $\left(\mathrm{N}_{2}\right)$. The local (lower) ideal optimum 
for neat lithium near that same mixture ratio corresponds to the lithium forming lithium oxide ( $\mathrm{Li}_{2} \mathrm{O}$, liquid), lithium chloride ( $\mathrm{LiCl}$, gaseous), and lithium hydroxide $(\mathrm{LiOH})$, the carbon from the binder produces $\mathrm{CO}$, the remaining hydrogen forms gaseous $\mathrm{H}_{2}$, and the nitrogen forms $\mathrm{N}_{2}$. The ideal global optimum for the lithium ternary system occurs when nearly all of the lithium forms $\mathrm{LiCl}$, the carbon in the binder produces $\mathrm{CO}_{2}$, the hydrogen forms water vapor $\left(\mathrm{H}_{2} \mathrm{O}\right)$, and the nitrogen forms $\mathrm{N}_{2}$; note that there are ideally no condensed phase species at this mixture ratio. This comparison of neat aluminum and neat lithium illustrates that when lithium is in an APCP system, it will favor the formation of gaseous $\mathrm{LiCl}$ to formation of an oxide.

Using an Al-Li alloy results in one global optimum $\mathrm{I}_{\mathrm{SP}}$ with increased performance over an expanded formulation envelope encompassing optimal performance regions of both neat Al and neat Li additive propellants (see Fig. 2D). This optimum corresponds to: complete oxidation of the aluminum (liquid $\mathrm{Al}_{2} \mathrm{O}_{3}$ ); near complete chlorination of lithium ( $\mathrm{LiCl}$ ); oxidation of carbon from the binder to form $\mathrm{CO}$; and formation of $\mathrm{N}_{2}$ and $\mathrm{H}_{2}$ as the primary product species. This combination leads to a lower combustion product molecular mass and higher specific impulse than either of the neat parent materials due to a number of factors. The replacement of some aluminum with lithium in the alloy results in some alumina product (molecular mass of $101.9 \mathrm{~g} \mathrm{~mol}^{-1}$ ) being replaced with $\mathrm{LiCl}$ (molecular mass of $42.4 \mathrm{~g} \mathrm{~mol}^{-1}$ ). Furthermore, alumina will predominantly stay in the condensed phase throughout the combustion event (boiling point of $2977{ }^{\circ} \mathrm{C}$, $1 \mathrm{~atm}$ ), whereas $\mathrm{LiCl}$ will primarily remain gaseous (boiling point of $1382{ }^{\circ} \mathrm{C}, 1$ atm). In some cases, the $\mathrm{LiCl}$ may condense out during nozzle expansion, but a chamber pressure of $68.0 \mathrm{~atm}$, optimally expanded to $1.0 \mathrm{~atm}$, results in an ideal nozzle exit temperature of 2070 ${ }^{\circ} \mathrm{C}$, well above the boiling temperature of $\mathrm{LiCl}$. Additionally, replacing $\mathrm{HCl}$ (molecular mass of $36.5 \mathrm{~g} \mathrm{~mol}^{-1}$ ) with $\mathrm{LiCl}$ only moderately increases the chlorine-based species molecular mass, but significantly lowers the global molecular mass by freeing up excess hydrogen gas (molecular mass of $2.0 \mathrm{~g} \mathrm{~mol}^{-1}$ ).

When $\mathrm{NaNO}_{3}$ is used to scavenge the chlorine ion (replacing a portion of the AP, see Fig. 2C), a similar trend in combustion products was observed: complete oxidation of the aluminum into $\mathrm{Al}_{2} \mathrm{O}_{3}$; complete chlorination of sodium $(\mathrm{NaCl})$; oxidation of the carbon from the binder to form $\mathrm{CO}$; nitrogen forms $\mathrm{N}_{2}$; and $\mathrm{H}_{2}$ is the primary product species for ideal products. In this case, however, the addition of sodium yields a significant increase in product molecular mass and therefore a decrease in specific impulse. 
Comparing the various Al-Li alloys (see Fig. 3) indicates that specific impulse steadily increases with increasing lithium content (for lithium contents $\leq 30$ mass $\%$ ). It is shown in Table 2 and Fig. 2 that the specific impulse will eventually begin to decrease (at some lithium content $\geq 30$ mass \%) as neat lithium has similar maximum performance to neat aluminum. The HPHS values for these systems also increase with lithium content and reaches near $100 \%$ at lithium contents $\geq 15$ mass $\%$. However, at lithium contents above $15 \%$, excess lithium yields significant amounts of products that are not $\mathrm{LiCl}$ (i.e., not enough chlorine in the ternary system to fully chlorinate the lithium available). Additionally, at higher lithium contents ( $\geq 15 \%)$, the low density of lithium begins to suppress the increase to specific impulse, yielding an ideal density impulse (the product of specific impulse and density) that is below neat aluminum. 

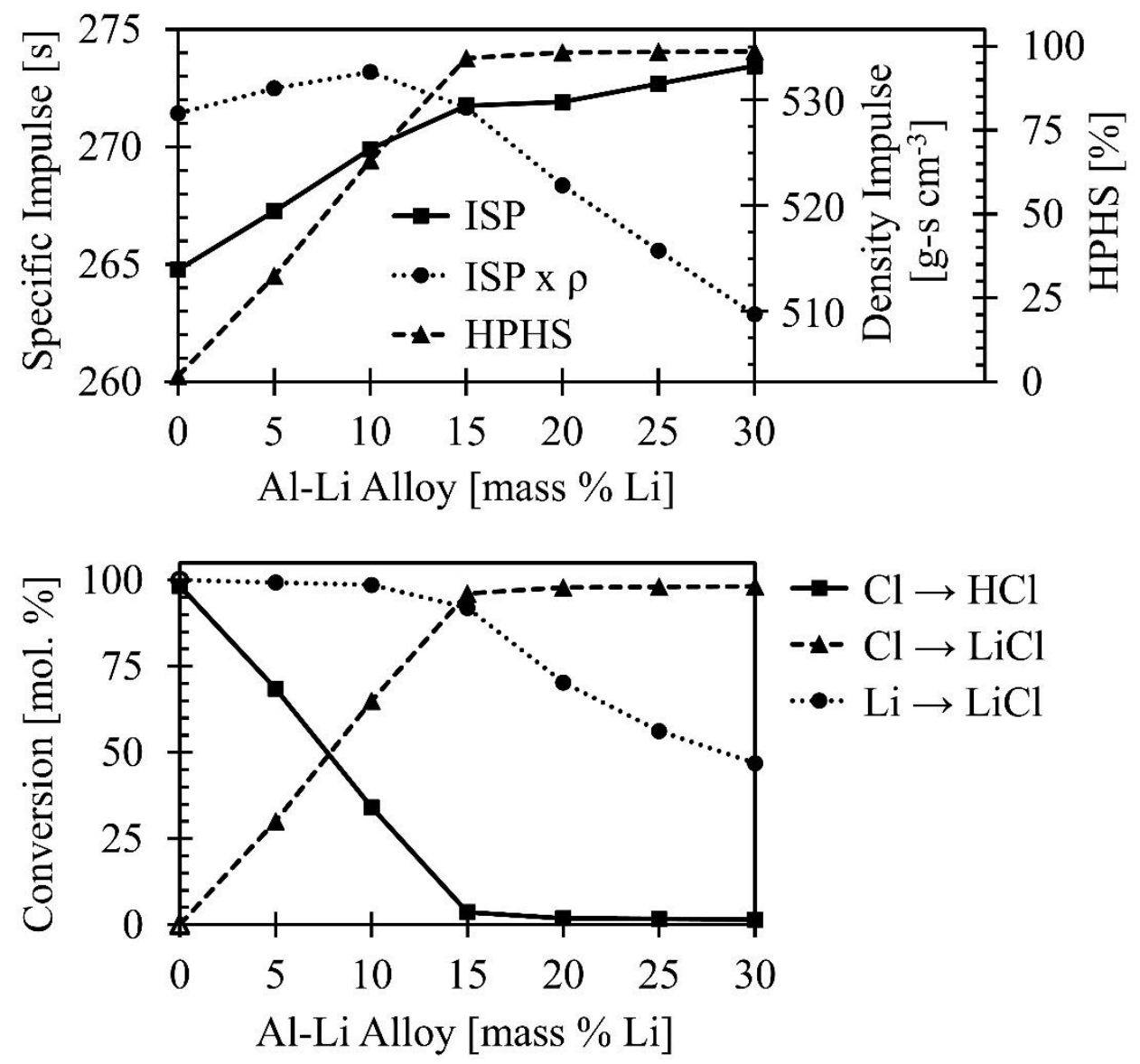

Figure 3. Thermochemical equilibrium predictions for Al-Li alloy/AP/HTPB ternary propellant formulations (lithium contents ranging from 0 to 30 mass \%) showing: (Top) the peak predicted specific impulse, the corresponding density impulse, and HPHS; and (Bottom) the corresponding conversion of chlorine and lithium to $\mathrm{HCl}$ and $\mathrm{LiCl}$.

\subsection{Solid Propellant Formulation and Combustion Characteristics}

Initial characterization of the as-received Al-Li alloy ( $\mathrm{LiAl}$ intermetallic phase) indicated that the powder was air-stable, but in the presence of water would induce a reaction with excess water (bubbling at the particle surfaces due to $\mathrm{Li}$ forming $\mathrm{LiOH}$ and $\mathrm{H}_{2}$ ). Consequently, we expect our HTPB based propellants to not be long-term stable since HTPB does not protect water or oxygen sensitive materials [37]. Other binders or particle coatings will need to be pursued in future work. Imaging and particle sizing of the sieved neat aluminum and 80/20 Al-Li alloy powders (Figs. 4-5) showed that neat aluminum was nominally equiaxed in morphology and that 
80/20 Al-Li alloy had an irregularly faceted morphology, typically with sharp/brittle surface features. The neat aluminum and Al-Li alloy powders had mean particle sizes (arithmetic) of $17.1 \mu \mathrm{m}$ and $29.8 \mu \mathrm{m}$ and volume weighted mean particle sizes $\left(\mathrm{D}_{[4,3]}\right)$ of $19.3 \mu \mathrm{m}$ and $33.3 \mu \mathrm{m}$ respectively.

Qualitatively, it appeared that the finer surface features (i.e., higher specific surface area) of the Al-Li particles did increase the working viscosity of the wetted propellant during and after mixing compared to the equivalent neat aluminum propellant. However, it should be noted that the solids loading of these propellants was quite high (88.3\%, see Table 1), which typically yields challenging mixture rheology. Using a lower solids loading (e.g., 85\%) may make the propellant rheology much more conducive to mixing and casting. In scaled up use, roller and dispersion mills may also be used to improve the Al-Li particle morphology and resultant mix rheology, as is done with AP [38].

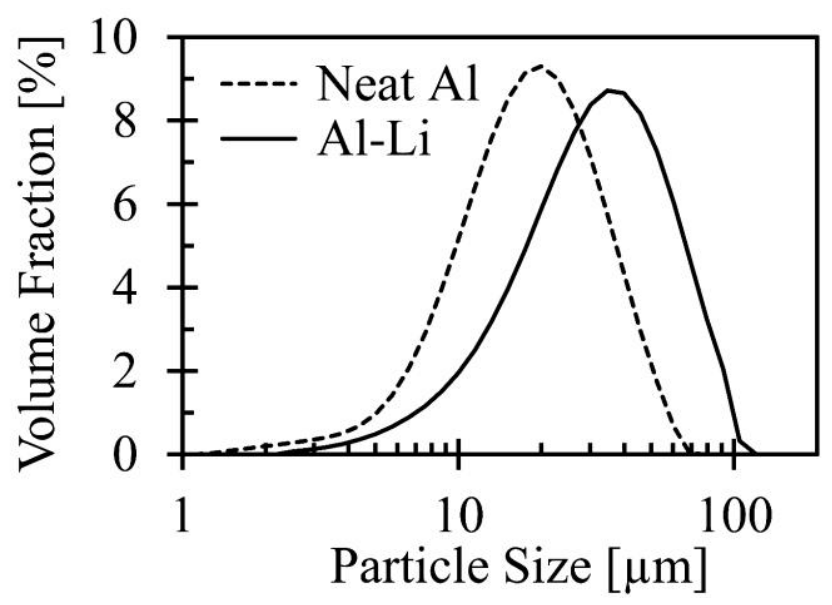

Figure 4. Particle sizing of the neat aluminum and 80/20 Al-Li alloy powders used in this study. 


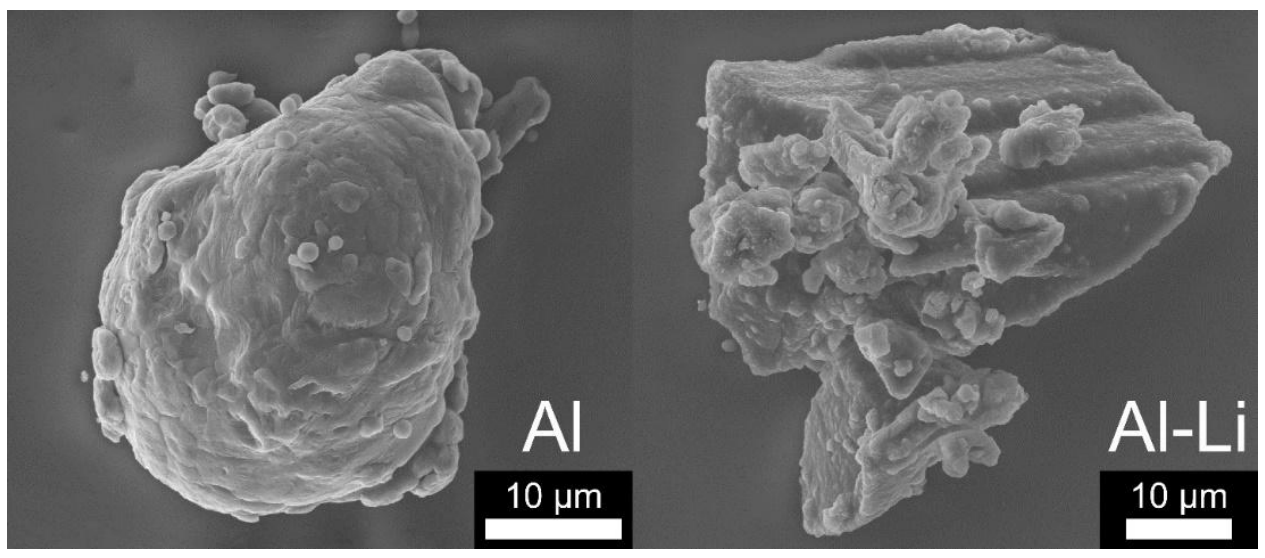

Figure 5. Typical SEM images showing particle morphology for the neat aluminum and 80/20 Al-Li alloy used in this study. All images were taken at $10.0 \mathrm{kV}$ and at a working distance of 5.2 $\mathrm{mm}$.

The combustion characteristics varied greatly between the Al and Al-Li propellants. The propellant testing was performed in air at room temperature and atmospheric pressure. Images of the burning plumes are shown in Fig. 6 and supplemental videos can be found online. Neat aluminized propellant burning surfaces were dominated by large, bright aluminum droplets lifting off of the propellant surface. Droplets were suspended briefly above the burning surface, and then gently fell. The Al-Li propellant was characterized by a large, bright magenta flame (often chaotic at times) and a relatively dark propellant surface. The magenta flame is indicative of $\mathrm{LiCl}$ emission. Very few coarse droplets were observed ejecting from the Al-Li surface. This was a significant observation given the high metal loading.

Large condensed phase agglomerates are undesirable in rocket propellants. They can contribute to two-phase flow losses (thermal and viscous disequilibrium through the nozzle), which can reduce overall motor performance by as much as $10 \%$ [1, 23, 39]. Additionally, large condensed phase droplets have been shown to cause combustion inefficiencies, energy losses from the combustion products to the rocket motor hardware (i.e., heat loss and droplet impingement), and boundary layer losses; together, these losses can contribute an additional 2$8 \%$ overall performance loss [1]. Therefore, it is anticipated that Al-Li will not only have a higher ideal specific impulse over neat aluminum, but will also yield much higher overall motor efficiencies due to the apparent reduction in agglomerate droplet size. Future work will 
investigate this apparent reduction in agglomerate droplet size, will further characterize the Al-Li propellant system (e.g., sensitivity, ageing, mixing rheology, etc.), and will ultimately test Al-Li propellant in a laboratory-scale rocket motor configuration in order to quantify the delivered increase in overall motor efficiency.
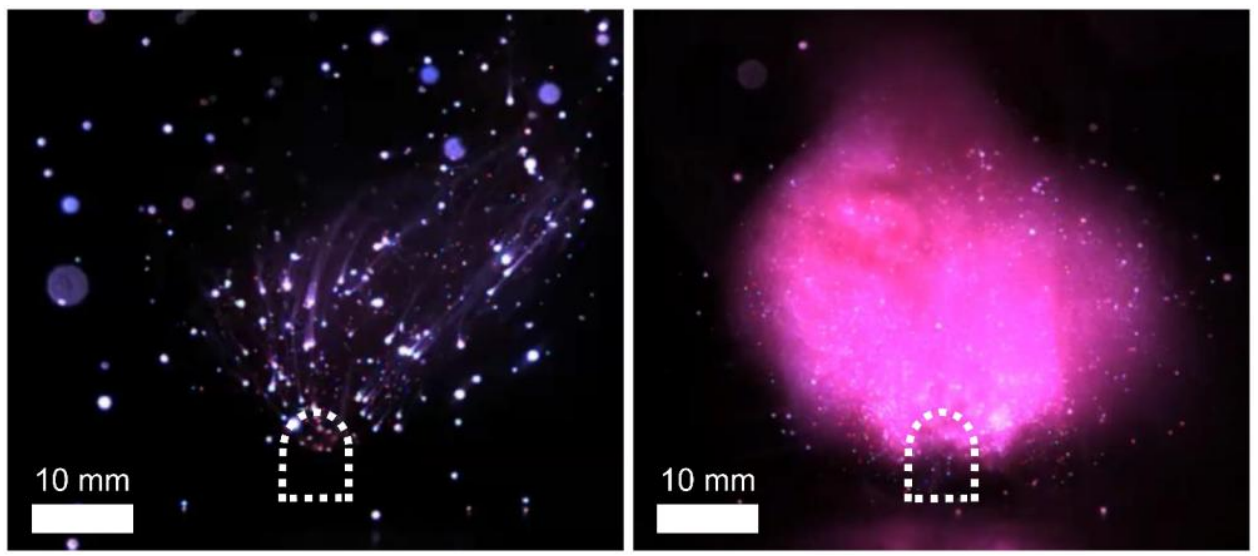

Figure 6. LEFT: APCP with a neat aluminum fuel additive. RIGHT: APCP with an 80/20 Al-Li fuel additive. The dotted lines represent the propellant surface location and geometry. All exposures are $10 \mu \mathrm{s}$. A color version of this figure can be found in the online manuscript.

\subsection{Hydrochloric Acid Detection}

The reduction in hydrochloric acid for Al-Li based propellants was evaluated using two methods: 1.) wet bomb combustion experiments and 2.) DSC/TGA coupled with simultaneous mass spectrometry and FTIR. For the wet bomb combustion experiments, a pH of $2.10 \pm 0.04$ was measured for the aluminum propellant and a $\mathrm{pH}$ of $2.71 \pm 0.08$ for the Al-Li propellant. This results in a $75.5 \pm 4.8 \%$ reduction of $\left[\mathrm{H}^{+}\right]$, which is proportional to the relative change in $\mathrm{HCl}$ concentration. The ideal $[\mathrm{HCl}]$ reduction between the two propellants is $91 \%$ at this mixture ratio and pressure. It is possible that the small scale of the experiment inhibited complete combustion of the propellants due to quenching of the plume against the cold chamber walls and water, causing the theoretical and measured values to vary. However, the $\mathrm{HCl}$ reduction is still significant. This experiment has been shown to be representative of other methods employed to 
quantify $\mathrm{HCl}$ content within rocket motor plumes [3, 11, 12] and similar losses to complete combustion have been observed [3].

The DSC/TGA-MS traces for neat AP (Fig. 7) suggests that there is an endothermic crystallographic phase change from orthorhombic to cubic [40] at roughly $240{ }^{\circ} \mathrm{C}$ (no gas evolution detected), which is followed by a broad exothermic decomposition at roughly $300{ }^{\circ} \mathrm{C}$ (evolution of $\mathrm{N}_{2} \mathrm{O}$, NO, and $\mathrm{H}_{2} \mathrm{O}$ detected). This broad decomposition is followed by a rapid exothermic decomposition, with an onset at approximately $410{ }^{\circ} \mathrm{C}$ (evolution of $\mathrm{HCl}, \mathrm{N}_{2} \mathrm{O}, \mathrm{NO}$, $\mathrm{H}_{2} \mathrm{O}$, and $\mathrm{O}_{2}$ detected), resulting in a total mass loss of $75 \%$. A nearly identical trend is apparent with the addition of aluminum (Fig. 8), indicating that the presence of aluminum has little effect on the low heating rate decomposition mechanisms of AP. In particular, the only noted deviations from neat AP were: 1.) significant reduction of $\mathrm{N}_{2} \mathrm{O}$ evolution during the broad exothermic AP decomposition at roughly $300^{\circ} \mathrm{C}$; and 2.) the clear presence of an aluminum melt endotherm at $660{ }^{\circ} \mathrm{C}$.

When AP is in the presence of 80/20 Al-Li (Fig. 9), exothermic decomposition of AP is reduced to approximately $180{ }^{\circ} \mathrm{C}$ (evolution of $\mathrm{NH}_{3}, \mathrm{NO}, \mathrm{N}_{2} \mathrm{O}$, and $\mathrm{H}_{2} \mathrm{O}$ detected), coincident with the melting point of lithium. The exothermic decomposition is immediately followed by a very weak endothermic phase change at roughly $240{ }^{\circ} \mathrm{C}$ (no new gas evolution detected). A second, rapid exothermic decomposition onsets at $360{ }^{\circ} \mathrm{C}$ (evolution of $\mathrm{NH}_{3}, \mathrm{NO}, \mathrm{N}_{2} \mathrm{O}, \mathrm{H}_{2} \mathrm{O}$, and $\mathrm{O}_{2}$ detected), followed by a third exothermic decomposition onset at approximately $420{ }^{\circ} \mathrm{C}$ (evolution of $\mathrm{NH}_{3}$ and $\mathrm{O}_{2}$ detected). The exothermic processes were then followed by three distinct endothermic events at roughly $540{ }^{\circ} \mathrm{C}, 600{ }^{\circ} \mathrm{C}$, and $660{ }^{\circ} \mathrm{C}$ (no new gas evolution detected). The last endotherm at $660{ }^{\circ} \mathrm{C}$ corresponds to the melting temperature of neat aluminum; the melting point of $80 / 20 \mathrm{Al}-\mathrm{Li}$ alloy is $695^{\circ} \mathrm{C}[32,41]$, suggesting that lithium was extracted from the $\mathrm{Al}-\mathrm{Li}$ phase prior to $660{ }^{\circ} \mathrm{C}$, likely at the $180{ }^{\circ} \mathrm{C}$ exotherm. The roughly 600 ${ }^{\circ} \mathrm{C}$ endotherm may correspond to either the eutectic melting point in the Al-Li phase diagram $\left(596{ }^{\circ} \mathrm{C}\right.$, at 26 at.\% lithium [32]) or the melting point of $\mathrm{LiCl}\left(605^{\circ} \mathrm{C}\right)$, which would indicate that $\mathrm{LiCl}$ formation had occurred prior to that temperature at one or more of the previous exothermic events. Further efforts are needed to elucidate the cause of the broad endothermic event at 540 ${ }^{\circ} \mathrm{C}$. It is significant to note that no $\mathrm{HCl}$ evolution was detected in the Al-Li/AP system. Furthermore, the presence of Al-Li alloy was able to reduce AP decomposition significantly 
from roughly $300{ }^{\circ} \mathrm{C}$ to $180{ }^{\circ} \mathrm{C}$ (well below the AP crystallographic phase change), likely due to $\mathrm{LiCl}$ formation.

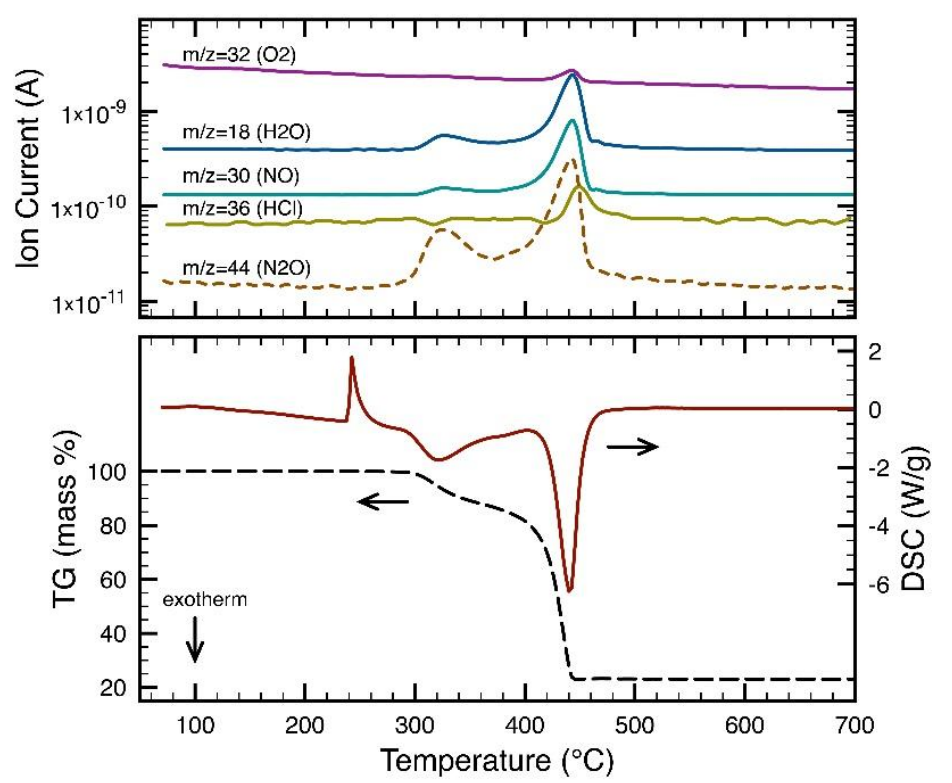

Figure 7. DSC/TGA and online ion currents from heating $\left(20^{\circ} \mathrm{C} \min ^{-1}\right)$ of neat AP. A color version of this figure can be found in the online manuscript. 

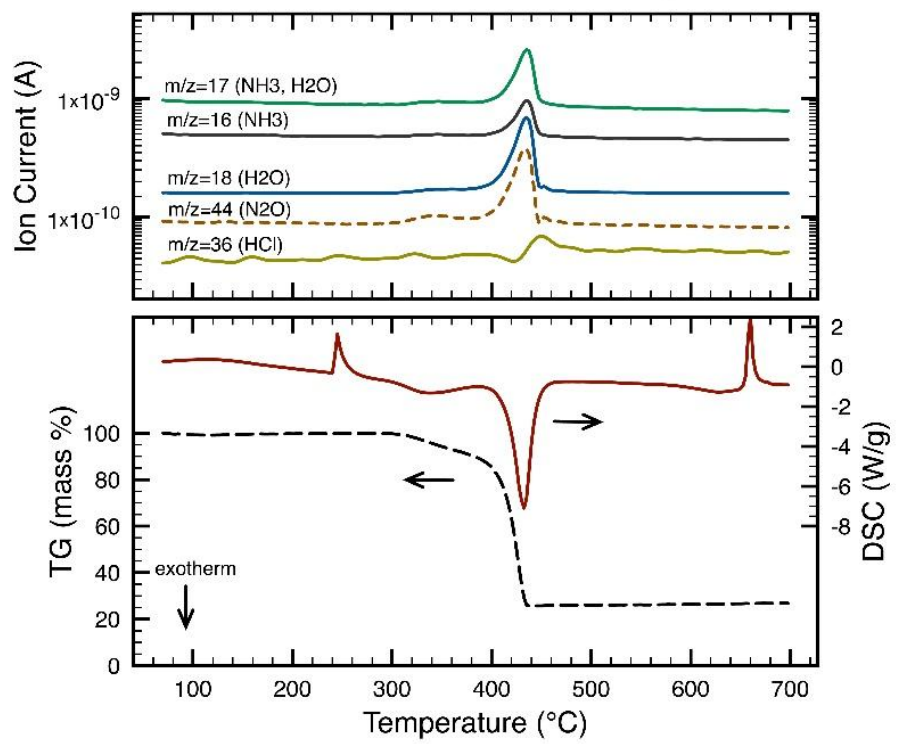

Figure 8. DSC/TGA and online ion currents from heating $\left(20^{\circ} \mathrm{C} \mathrm{min}^{-1}\right)$ of $30 / 70$ mass $\% \mathrm{Al} / \mathrm{AP}$. A color version of this figure can be found in the online manuscript.

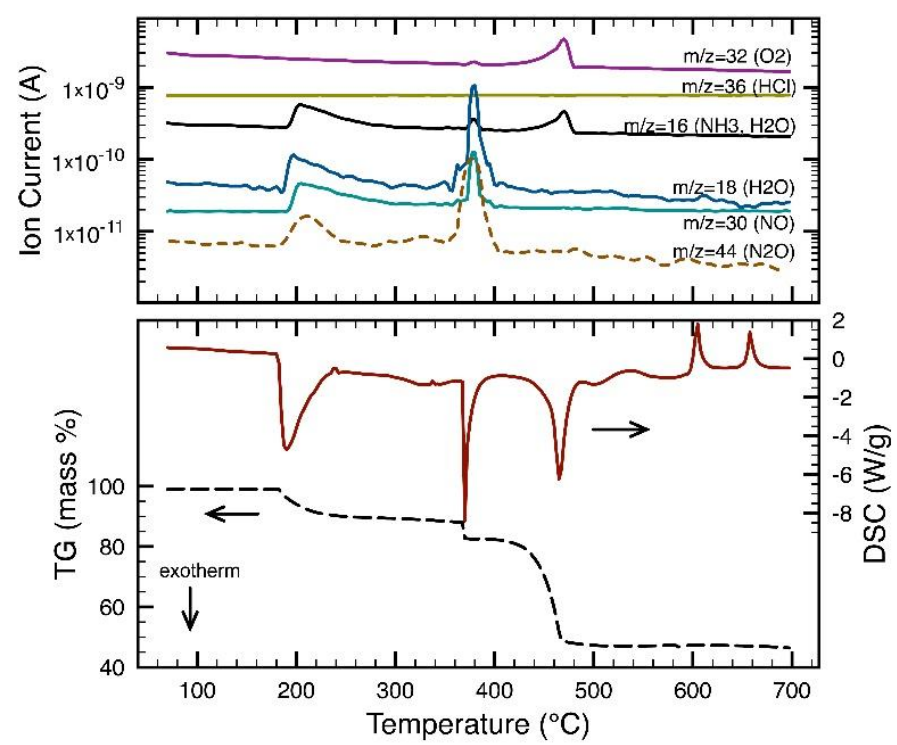

Figure 9. DSC/TGA and online ion currents from heating $\left(20{ }^{\circ} \mathrm{C} \min ^{-1}\right)$ of $30 / 70$ mass \% Al$\mathrm{Li} / \mathrm{AP}$. A color version of this figure can be found in the online manuscript. 
Consistent with online MS results, FTIR measurements (Fig. 10) confirmed that neat AP yields a strong $\mathrm{HCl}$ vibration band between $3100-2600 \mathrm{~cm}^{-1}$ at approximately $450{ }^{\circ} \mathrm{C}$. However, from FTIR measurements, it was also apparent that there is low-level formation of $\mathrm{HCl}$ at roughly $320{ }^{\circ} \mathrm{C}$, coincident with the first exotherm shown in Fig. 7; this low-level $\mathrm{HCl}$ formation may have been below the detection threshold of the mass spectrometer. Virtually identical $\mathrm{HCl}$ vibrational bands at the same temperatures were evident with Al/AP FTIR measurements (not shown), again indicating that the presence of aluminum has little, if any, effect on the low heating rate $\mathrm{HCl}$ evolution from AP decomposition. The FTIR measurements between 3100$2600 \mathrm{~cm}^{-1}$ from Al-Li/AP indicates that there are some broad absorption features above $2800 \mathrm{~cm}^{-}$ ${ }^{1}$ near $180{ }^{\circ} \mathrm{C}$ and $360{ }^{\circ} \mathrm{C}$ (coincident with Al-Li/AP exothermic peaks), but no strong $\mathrm{HCl}$ vibrational bands are detected at any temperatures. Close observation of the Al-Li/AP plots indicates that there may be some low-level $\mathrm{HCl}$ vibrational bands evident above $360{ }^{\circ} \mathrm{C}$, but absorption signal levels are near the instrument noise floor, making $\mathrm{HCl}$ detection speculative.
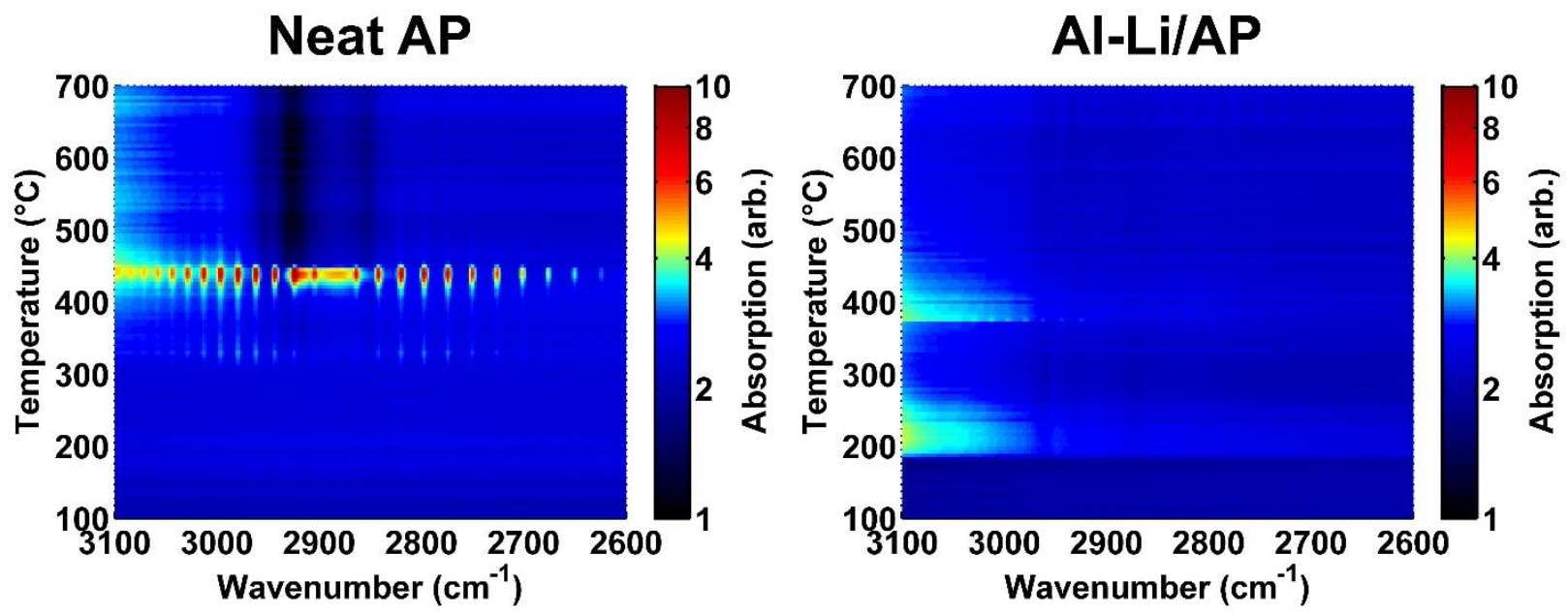

Figure 10. FTIR absorption spectra between 3100-2600 $\mathrm{cm}^{-1}$ (HCl evolution) from decomposition of AP (left) and 30/70 mass \% Li-Al/AP (right). A color version of this figure can be found in the online manuscript. 


\section{Conclusions}

The aluminum-lithium binary alloy was evaluated both theoretically and experimentally as a high performance halide scavenger in AP composite propellant formulations, meaning that it can significantly reduce $\mathrm{HCl}$ formation as well as increase the ideal specific impulse. The following conclusions can be made from this work:

1. Thermochemical equilibrium calculations indicate that all Al-Li alloys with $\mathrm{Li}$ content $\leq 30$ mass $\%$ have improved ideal specific impulse over both neat aluminum and neat lithium.

2. Lithium contents above 15 mass $\%$ ideally result in near complete elimination of $\mathrm{HCl}$ at peak $\mathrm{I}_{\mathrm{SP}}$ values, yielding HPHS values greater than $95 \%$.

3. Propellants containing 80/20 mass \% Al-Li alloy ( $\mathrm{LiAl}$ intermetallic phase) yield a significant reduction in $\mathrm{HCl}$ formation, verified using two methods: A.) Wet bomb experiments resulted in a $75.5 \pm 4.8 \%$ reduction in acidity $(\propto[\mathrm{HCl}])$, and B.) DSC/TGA coupled with MS and FTIR did not detect any $\mathrm{HCl}$ evolution of 30/70 mass \% Al-Li/AP mixtures.

These results indicate that fuel additives based on the Al-Li binary system are promising candidates for high performance halide scavenger propellants, while also improving ideal $\mathrm{I}_{\mathrm{SP}}$ values. However, further efforts are needed to characterize this propellant, as well as protect the Al-Li from moisture/air in new formulations, and determine its potential viability as a fielded solid rocket propellant.

\section{Acknowledgements}

This research was conducted with Government support under and awarded by DoD, Air Force Office of Scientific Research, National Defense Science and Engineering Graduate (NDSEG) Fellowship, 32 CFR 168a. The authors would also like to acknowledge funding provided by both the Purdue Forever fellowship and AFOSR MURI contract (\#FA9550-13-1-0004) with Mitat Birkan as Program Manager. 


\section{References}

[1] Y.M. Timnat, Advanced Chemical Rocket Propulsion, Academic Press, Orlando, FL, 1987.

[2] B.D. Andrea, F. Lillo, Industrial Constraints for Developing Solid Propellants with Energetic Materials, Journal of Propulsion and Power, 15 (1999) 713-718.

[3] B. D'Andrea, F. Lillo, A. Faure, C. Perut, A new generation of solid propellants for space launchers, Acta Astronaut, 47 (2000) 103-112.

[4] R.R. Bennet, Low Acid Producing Solid Propellants, in: Aerospace Environmental Technology Conference, NASA. Marshall Space Flight Center, 1995.

[5] R.R. Bennet, "Clean" Propellants and the Environment, in: AIAA 28th Joint Propulsion Conference and Exhibit, Nashville, TN, 1992.

[6] D.B. Lempert, G.N. Nechiporenko, G.P. Dolganova, S.I. Soglasnova, Solid Composite Propellants of Low Pollution.

[7] W.J. Doucette, S. Mendenhall, L.S. McNeill, J. Heavilin, The sky is falling II: Impact of deposition produced during the static testing of solid rocket motors on corn and alfalfa, Science of The Total Environment, 482-483 (2014) 36-41.

[8] C. Oommen, S.R. Jain, Ammonium nitrate: a promising rocket propellant oxidizer, Journal of Hazardous Materials, 67 (1999) 253-281.

[9] M. Ross, D. Toohey, M. Peinemann, P. Ross, Limits on the Space Launch Market Related to Stratospheric Ozone Depletion, Astropolitics, 7 (2009) 50-82.

[10] D.K. McGrath, R.L. Willer, High performance large launch vehicle solid propellants, 5801325. Cordant Technologies Inc., 1998.

[11] D.W. Doll, G.K. Lund, Magnesium-neutralized propellant, Journal of Propulsion and Power, 8 (1992) 11851191.

[12] D.W. Doll, G.K. Lund, Magnesium-Netralized Clean Propellant, in: AIAA 27th Joint Propulsion Conference, Sacramento, CA, 1991.

[13] D.W. Doll, G.K. Lund, High performance, low cost solid propellant compositions producing halogen free exhaust, 5076868. Thiokol Corporation, 1991.

[14] D.W. Doll, G.K. Lund, M.J. Spinti, Solid propellant formualtions producing acid neutralizing exhaust, 5180452. Thiokol Corporation, 1993.

[15] J. Hyyppa, High energy composition, 4642147. Raikka Oy, 1987.

[16] V. Kanazirev, J. Gorawara, H. Rastelli, P. Rumfola, Halide scavengers for high temperature applications, 2007061607. 2007.

[17] R.S. Scheffee, B.K. Wheatley, Gas-generative composition consisting essentially of ammonium perchlorate plus a chlorine scavenger and an organic fuel, 5861571. Atlantic Research Corporation, 1999.

[18] D.A. Reese, S.F. Son, L.J. Groven, Composite Propellant Based on a New Nitrate Ester, Propellants, Explosives, Pyrotechnics, 39 (2014) 684-688.

[19] A.W. Blackman, D.K. Kuehl, Use of Binary Light Metal Mixtures and Alloys as Additives for Solid Propellants, ARS Journal, 31 (1961) 1265-1272.

[20] D.K. Kuehl, Solid propellants, 3133841. United Aircraft Corp, 1964.

[21] D.K. Kuehl, Propellant compositions containing oxyphylic and halophylic metals, 3133842. United Aircraft Corp, 1964.

[22] D.K. Kuehl, Ignition and combustion of aluminum and beryllium, AIAA Journal, 3 (1965) 2239-2247.

[23] G.P. Sutton, O. Biblarz, Rocket Propulsion Elements, 8th ed., Wiley. com, 2011.

[24] R.W. Humble, G.N. Henry, W.J. Larson, Space Propulsion Analysis and Design, McGraw-Hill, New York, NY, 1995.

[25] R.J.H. Wanhill, Chapter 15 - Aerospace Applications of Aluminum-Lithium Alloys, in: N.E. Prasad, A.A. Gokhale, R.J.H. Wanhill (Eds.) Aluminum-lithium Alloys, Butterworth-Heinemann, Boston, 2014, pp. 503-535.

[26] E.-C. Koch, C. Jennings-White, Is it possible to Obtain a Deep Red Pyrotechnic Flame Based on Lithium?, in: 36th International Pyrotechnics Seminar, Rotterdam, Netherlands, 2009.

[27] S. Bastea, L.E. Fried, K.R. Glaesemann, W.M. Howard, I.-F. Kuo, P.C. Souers, P.A. Citello, Cheetah 7.0, in, Lawrence Livermore National Laboratory, 2012.

[28] W. Gąsior, A. Dębski, A. Góral, R. Major, Enthalpy of formation of intermetallic phases from Al-Li system by solution and direct reaction calorimetric method, Journal of Alloys and Compounds, 586 (2014) 703-708. 
[29] N.P. Yao, L.A. Herédy, R.C. Saunders, Emf Measurements of Electrochemically Prepared Lithium-Aluminum Alloy, Journal of The Electrochemical Society, 118 (1971) 1039-1042.

[30] N. Saunders, Calculated stable and metastable phase equilibria in Al-Li-Zr alloys, Zeitschrift fuer Metallkunde/Materials Research and Advanced Techniques, 80 (1989) 894-903.

[31] C. Sigli, J.M. Sanchez, Calculation of phase equilibrium in Al-Li alloys, Acta Metallurgica, 34 (1986) 10211028.

[32] A.J. McAlister, The Al-Li (Aluminum-Lithium) system, Bulletin of Alloy Phase Diagrams, 3 (1982) 177-183.

[33] S.-W. Chen, C.-H. Jan, J.-C. Lin, Y.A. Chang, Phase equilibria of the Al-Li binary system, MTA, 20 (1989) 2247-2258.

[34] N.E. Christensen, Structural phase stability of B2 and B32 intermetallic compounds, Physical Review B, 32 (1985) 207-228.

[35] X.Q. Guo, R. Podloucky, A.J. Freeman, Structural and electronic structural properties of ordered LiAl compounds, Physical Review B, 40 (1989) 2793-2800.

[36] A.H. Yan, S.F. Son, T.L. Jackson, P. Venugopal, Validation of Numerical Simulations for Nano-Aluminum Composite Solid Propellants, Journal of Propulsion and Power, 27 (2011) 1280-1287.

[37] S.C. Shark, T.L. Pourpoint, S.F. Son, S.D. Heister, Performance of Dicyclopentadiene/H2O2-Based Hybrid Rocket Motors with Metal Hydride Additives, Journal of Propulsion and Power, 29 (2013) 1122-1129.

[38] J.R. Mackey, E.T. Foster, High Performance Fast Burning Solid Propellant, 4070212. Thiokol Corporation, 1978.

[39] H. Cheung, N.S. Cohen, Performance of solid propellants containing metal additives, AIAA Journal, 3 (1965) 250-257.

[40] N.B. Singh, A.K. Ojha, Formation of copper oxide through NaNO3-KNO3 eutectic melt and its catalytic activity in the decomposition of ammonium perchlorate, Thermochimica Acta, 390 (2002) 67-72.

[41] N.E. Prasad, T.R. Ramachandran, Chapter 3 - Phase Diagrams and Phase Reactions in Al-Li Alloys, in: N.E. Prasad, A.A. Gokhale, R.J.H. Wanhill (Eds.) Aluminum-lithium Alloys, Butterworth-Heinemann, Boston, 2014, pp. 61-97. 